\title{
Editorial
}

\section{Ischemic Stroke Prevention}

Antonino Tuttolomondo, MD, $\mathrm{PhD}$

Dipartimento Biomedico di Medicina Interna e Specialistica, Università degli Studi di Palermo

Ischemic Stroke Prevention Stroke is the second leading cause of death worldwide as well as the leading cause of long-term disability, with around 500 transient ischemic attacks (TIAs) and 2,400 new strokes per 1,000,000 inhabitants each year [1]. One third of new stroke patients (700) die each year and less than half recover and regain their independence [2]. Stroke prevention is a crucial issue, given that stroke is a frequent and severe disorder, and acute stroke therapies, which are effective at the individual level, have only a limited impact on public health. Vascular risk factors should be treated to prevent ischemic stroke, especially high blood pressure, high blood cholesterol and cigarette smoking. Stroke is a life-changing event that affects not only the person who may be disabled, but the entire family and other caregivers as well. Utility analyses show that a major stroke is viewed by more than half of those at risk as being worse than death [3]. Despite the advent of treatment of selected patients with acute ischemic stroke with intravenous tissue-type plasminogen activator and the promise of other acute therapies, effective prevention remains the best treatment for reducing the burden of stroke [4,5]. Primary prevention is particularly important because $>70 \%$ of strokes are first events [2]. Nevertheless, observational studies have documented relationships between initial stroke, vascular risk factors (e.g., hypertension, diabetes, hyperlipidemia), and lifestyle risk factors (e.g., smoking, alcohol use, obesity, lack of physical activity) [6-8]. Determining the cause of stroke does influence choices for management and determination of stroke subtype could influence prevention management. On this basis statins, antiplatelets have a clear indication in prevention of atherosclerotic subtypes of stroke, whereas the effectiveness of these drugs in prevention of lacunar subtype of stroke appear to be less indicated. Cardioembolic stroke prevention include anti-vitamin-k antagonists and antiplatelets but the possible effectiveness of statins and antihypertensive drugs should be better addressed.

Although the relationship between cholesterol plasma levels and stroke remains still controversial, several studies have demonstred a favourable effect of this class of drugs on lowering stroke risk. Furthermore meta-analysis of trials with statins at intensive dosage showed that its therapeutic way in a secondary prevention setting is able to reduce by $17 \%$ the risk of stroke [9]. In particular the Stroke Prevention by Aggressive Reduction in Cholesterol Levels (SPARCL) trial, atorvastatin $80 \mathrm{~m} /$ day in comparison with placebo significantly reduced stroke risk in patients with a recent history of acute cerebrovascular event $[10,11]$. The role of the rennin-angiotensin-aldosteron-system (RAAS) in process that lead to heart disease, stroke and kidney failure took a great leap forward when it became possible to antagonize this system. In the LIFE study [12] Losartan was better than atenolol in reducing the primary composite end point of cardiovascular mortality, stroke, and MI (unadjusted HR 0.85; 95\% CI, 0.76-0.96; $\mathrm{P}=.009$ ). This difference was primarily due to a $26 \%$ relative risk reduction (RRR) in stroke with losartan (unadjusted 0006). There have been numerous clinical trials looking at the use of ACE inhibitors and ARBs in HTN, HF, and other special populations. Overall, it has been noted that ACE inhibitors and ARBs appear to have an additional benefit beyond just the blood pressure-lowering effect when used in certain populations. Medical management of patients with atrial fibrillation (AF) at high risk for stroke is limited by problems of imperfect tools for assessment of thromboembolism and bleeding risks. Improved instruments, such as the $\mathrm{CHA}_{2} \mathrm{DS}_{2} \mathrm{VASc}$ and HAS-BLED risk stratification scores, have been incorporated into European practice guidelines. Until recently, the most effective therapy for stroke prevention has been anticoagulation with a vitamin $\mathrm{K}$ antagonist, but new oral anticoagulants in development, antiarrhythmic drugs that reduce adverse cardiovascular events in patients with $\mathrm{AF}$, and interventional techniques for occlusion of the left atrial appendage represent promising options for stroke prevention. On this basis, determining the cause of stroke does influence choices for management. Nevertheless, most trials did not evaluated stroke according stroke subtypes and on this basis few studies exist about the role of drug prevention in lacunar stroke or cardioembolic stroke, and only more recent studies considered stroke prevention in relation of clinical subtypes of stroke classified according TOAST subtype. Another important feature of classifying stroke subtypes is also represented by immunoinflammatory degree of each diagnostic subtype that several studies [13-17] demonstred could be strictly related to stroke diagnosis, stroke size and prognosis, so representing an additional factor to evaluate in a clinical context of prevention strategies of ischemic stroke. 


\section{REFERENCES}

[1] Lloyd-Jones D, Adams R, Carnethon M, et al. American Heart Association: Heart disease and stroke. Statistics 2009. Update. Circulation 2009;119:e1-e161.

[2] American Heart Association. Heart Disease and Stroke Statistics_-2004 Update. Dallas, Tex: American Heart Association; 2003.

[3] Samsa GP, Matchar DB, Goldstein L, et al. Utilities for major stroke: results from a survey of preferences among persons at increased risk for stroke. Am Heart J 1998; 136: 703-713.

[4] Adams H, Adams R, Del Zoppo G, Goldstein LB; Stroke Council of the American Heart Association; American Stroke Assocation. Guidelines for the early management of patients with ischemic stroke: 2005 guidelines update: a scientific statement from the Stroke Council of the American Heart Association/American Stroke Association (published corrections appear in Stroke. 2005;36:1626 and Stroke 2005;36:135 2). Stroke 2005; 36: $916-923$.

[5] Sacco RL, Benjamin EJ, Broderick JP, et al. American Heart Association Prevention Conference. IV. Prevention and Rehabilitation of Stroke Risk factors. Stroke 1997; 28: 1507-1517.

[6] Sacco RL, Adams R, Albers G, et al. Guidelines for prevention of stroke in patients with ischemic stroke or transient ischemic attack: a statement for healthcare professionals from the American Heart Association/American Stroke Association Council on Stroke: co-sponsored by the Council on Cardiovascular Radiology and Intervention: the American Academy of Neurology affirms the value of this guideline. Stroke 2006;37:577-617.

[7] RL, Teal P. Antithrombotic and thrombolytic therapy for ischemic stroke: the Seventh ACCP Conference on Antithrombotic and Thrombolytic Therapy. Chest 2004; 126(3 suppl) 483S-512S.

[8] Chobanian AV, Bakris GL, Black HR, et al., for the National Heart, Lung, and Blood Institute Joint National Committee on Prevention, Detection Evaluation, and Treatment of High Blood Pressure, and the National High Blood Pressure Education Program Coordinating Committee. The Seventh Report of the Joint National Committee on Prevention, Detection, Evaluation, and Treatment of High Blood Pressure: the JNC 7 report [Published correction appears in JAMA 2003;290:197]. JAMA 2003;289:2560-72.

[9] Baigent C, Keech A, Kearney PM, et al. Efficacy and safety of cholesterol-lowering treatment: prospective meta-analysis of data from 90,056 participants in 14 randomised trials of statins. Lancet 2005; 366, 1267-1278 ().

[10] Amarenco P, Bogousslavsky J, Callahan A 3rd et al.; for the SPARCL Investigators: High-dose atorvastatin after stroke or transient ischemic attack. N Engl J Med 2006; 355(6): 549-555.

[11] Amarenco P, Goldstein LB, Szarek M, et al.; for the SPARCL Investigators: Effects of intense LDL-C reduction in patients with stroke or transient ischemic attack: the Stroke Prevention by Aggressive Reduction in Cholesterol Levels (SPARCL) trial. Stroke 2007; 38: 3198-3204.

[12] Dahlöf B, Devereux RB, Kjeldsen SE, et al. Cardiovascular morbidity and mortality in the Losartan Intervention For Endpoint reduction in hypertension study (LIFE): a randomised trial against atenolol. Lancet 2002;359:995-1003.

[13] Tuttolomondo A, Di Raimondo D, Di Sciacca R, et al. Arterial stiffness and ischemic stroke in subjects with and without metabolic syndrome.Atherosclerosis. 2012;225(1):216-9.

[14] Tuttolomondo A, Di Raimondo D, Pecoraro R, Arnao V, Pinto A, Licata G. Atherosclerosis as an inflammatory disease.Curr Pharm Des 2012;18(28):4266-88.

[15] Tuttolomondo A, Di Raimondo D, Pecoraro R, Arnao V, Pinto A, Licata G. Inflammation in ischemic stroke subtypes. Curr Pharm Des 2012;18(28):4289-310.

[16] Tuttolomondo A, Pinto A, Corrao S, et al. Immuno-inflammatory and thrombotic/fibrinolytic variables associated with acute ischemic stroke diagnosis. Atherosclerosis 2009;203(2):503-8.

[17] Tuttolomondo A, Di Sciacca R, Di Raimondo D, et al. Plasma levels of inflammatory and thrombotic/fibrinolytic markers in acute ischemic strokes: relationship with TOAST subtype, outcome and infarct site. J Neuroimmunol. 2009;215(1-2):84-9.

Antonino Tuttolomondo, MD, PhD

Dipartimento Biomedico di Medicina Interna e Specialistica,

Università degli Studi di Palermo (Italy),

P.zza delle Cliniche n.2, 90127 Palermo (Italy);

Tel: $+39 / 0916552128$

Fax: $+39 / 091 / 6552285$

E-mail: bruno.tuttolomondo@unipa.it 